\title{
Extending the use of thermal furrows for irrigation purposes
}

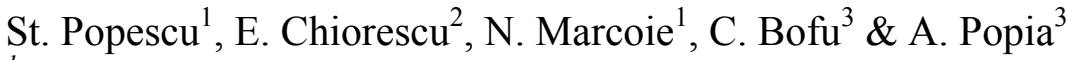 \\ ${ }^{I}$ Department of Hydroamelioration and Environment Protection, \\ Technical University "Gh. Asachi”, Iassy, Romania \\ ${ }^{2}$ Department of Pedology, Agronomic University, Iassy, Romania \\ ${ }^{3}$ Department of Cadastre, Technical University, Iassy, Romania
}

\begin{abstract}
Over the last decade the researchers have investigated solutions with original ideas for the development of land improvement by using geothermal water energy in Romania, and to extend therewith the usual vegetation period. Some of these solutions use thermal furrows, lined with impervious, heat-conductive plastic sheets interlaced between the crop rows, whose role is to heat the soil and the ambient air in the early spring and late autumn. The present paper investigates the possibility of employing horizontal thermal furrows over the whole crop-growing period as well as irrigation furrows. To this purpose, such a furrow should be obturated in a downstream section and then supplied with irrigation water of adequate quality. In a lined furrow, infiltration occurs along the furrow only on the perimeter situated above the upper edges of the plastic lining. The technical parameters of the lined furrow (value of the inflow, depth of the water and furrow length, shape of the section and distance between furrows) have been found by simultaneously considering two performance criteria: the maximization of field-watering effectiveness and the uniformity coefficient. As the resulting infiltration flow shows neither significant variation during the irrigation time, nor a dependence on the base level of the infiltrating water layer, the regime of flow in the furrow may be considered permanent, gradually varied, with a uniformly distributed discharge. Consequently, without any important additional investment, the thermal furrows can be used effectively as irrigation furrows, too.
\end{abstract}

Keywords: lined thermal furrows, irrigation furrows, zero gradient, permanent and gradually varied flow. 


\section{Introduction}

Because of the difficulties connected with the low efficiency of watering by surface flooding (the water-utilization factor is around 50-70\%), and with the non-uniform water distribution on the surface (uniformity coefficient about 50$60 \%$ ), in Romania irrigation with flooded furrows (supplied from a channel by siphons) does not exceed $6-7 \%$ of the overall surfaces that are provided with irrigation installations.

But if the equipment for the water distribution to the furrows will be upgraded or even automated, the furrow watering gets a better performance and becomes therewith more beneficial. On the base of researches in countries of the European Union (Portugal) and in the United States, which are presented in the Final Report [4], some technical solutions have been elaborated that have delivered good results in pilot stations, as well as in large farm applications. Under these new terms in the United States, for example, the surfaces equipped for watering by surface flooding have reached above $60 \%$ of the total areas arranged for irrigation.

Another solution for the uprating of the water-utilization factor, and for the improvement of the uniformity coefficient, consists in the coating of the furrows with a watertight foil or trough. However, in particular because of the high investment costs, such coated furrows have not yet been used in large-scale applications, and therefore they have not been studied systematically.

Presently, thanks to the innovative solution for the extension of the vegetation period by using the energy of thermal water transported through the thermal furrows, which has been proposed by Popescu and Giurma [1] and Nitescu et al. [2], appears the opportunity to utilize the lined thermal furrows - without greater additional costs - for irrigation purposes.

This article represents a first attempt of modeling and simulation of the water distribution through the thermal furrows. Depending on the future results, which will be attained by the researches in the domain of lined furrows, it can be decided if this kind of furrow will be efficient when deployed alone for irrigation purposes. Evidently, this method will be applied at first for the irrigation of economically efficient cultures, for vegetables and vineyards, or for surfaces with a heightened permeability.

\section{Conceptual model}

Popescu and Giurma [1] have considered the horizontal, lined thermal furrows as cylinders with a semi-circular section, which have a radius $R$ and a length $L_{f}$. The bottom of the furrow is located at a relative height (in rapport to a horizontal plane of reference) $y_{f}$. For the avoidance of soil pollution in every section $s$, the water depth has to satisfy the condition $h<R$. The soil of the plant rows has a bottom-up semicircular section, with the peak height at $y_{f}+2 R$.

However, if the furrows are supplied with a constant amount of irrigation water $\mathrm{Q}_{\text {ups }}$, for example out of a watering pipe with orifices, then can be 
Table 1: $\quad$ Moments and characteristic water depths at a watering with lined furrows.

\begin{tabular}{|l|c|c|l|}
\hline No. & $\begin{array}{c}\text { Moment } \\
(t)\end{array}$ & $\begin{array}{c}\text { Water } \\
\text { depth }(h)\end{array}$ & \multicolumn{1}{|c|}{ Commentary } \\
\hline 1 & $t_{0}^{\text {inc }}$ & $R$ & $\begin{array}{l}\text { the growing water level reaches the upper } \\
\text { edges of the coating }\end{array}$ \\
\hline 2 & $t_{\max }^{\text {inc }}$ & $h_{\max }$ & the maximal water level is stabilizing \\
\hline 3 & $t_{\max }^{\text {rem }}$ & $h_{\max }$ & $\begin{array}{l}\text { the water supply has been stopped and the } \\
\text { water level decreases }\end{array}$ \\
\hline 4 & $t_{0}^{\text {rem }}$ & $R$ & $\begin{array}{l}\text { the water level decreases till to the edges of the } \\
\text { coating }\end{array}$ \\
\hline
\end{tabular}

distinguished the following moments and characteristic water depths as presented in the table 1 .

In the time interval $\left[t_{0}^{i n c}, t_{0}^{\text {rem }}\right]$, the cultivated soil is supplied only by the infiltration that occurs through the wetted perimeter, which depends on the depth $h_{\text {over }}$ :

$$
h_{\text {over }}=h-R \text {, with } h_{\text {over }} \in\left[0, h_{\text {over }}^{\max }\right] \text { and } h_{\text {over }}^{\max }=h_{\max }-R .
$$

At the same time is lost water from the active soil stratum through evapotranspiration, but these losses can be disregarded during the process of watering.

For the infiltration process itself we have made the following assumptions: $1^{\mathrm{o}}$ - the soil has a loamy-sandy texture, is considered as a porous, homogeneous and isotropic medium, which is characterized by hydrogeological properties as follows: effective porosity, $n_{C}$, specific storage coefficient, $S_{s}$, hydroconductivity at saturation level (say the filtration coefficient), $K$;

$2^{\circ}$ - for the unsaturated state of the soil has been adopted the characteristic humidity curve according to the model of van Genuchten-Mualem, which is characterized by the maximal saturation, $S_{w}^{s}=1$, the residual saturation, $S_{w}^{r}$, the coefficient of the curve, $A_{w}$, and the curve exponent, $n_{w}$;

$3^{\mathrm{o}}$ - at the initial moment, $t_{I}=t_{0}^{i n c}$, the humidity of the active soil layer is distributed uniformly and it corresponds to a saturation degree, $S_{w}^{I}$, while at the final momental, $t_{F}=t_{0}^{r e m}$, the saturation degree on the uncoated perimeter of the furrow has the value $S_{w}^{F}$. Referring to the modes of flow in the lined furrows can further be adopted some simplifying assumptions:

$4^{\mathrm{o}}$ - for the interval $\left[t_{\max }^{i n c}, t_{\max }^{\text {rem }}\right]$ a permanent runoff regime, gradually varied, with an uniformly distributed discharge $\left[1\left[, q_{\max }=Q_{\text {ups }} / L_{f}\right.\right.$, with $Q_{u p s}$ the flowthrough, and a quasi constant depth $h \cong h_{\max }$; 
$5^{\circ}$ - in the intervals $\left[t_{0}^{i n c}, t_{\text {max }}^{i n c}\right]$ and $\left[t_{\text {max }}^{\text {rem }}, t_{0}^{\text {rem }}\right]$ there are transitory flow modes, but uniformly with regard to the water depth as well as to the distributed specific discharge:

$$
\partial h / \partial s \cong 0, \partial q / \partial s \cong 0 \cong 0, \text { for } s \in\left[0, L_{f}\right]
$$

Taking into account the hypotheses $4^{\circ}$ and $5^{\circ}$, the infiltration process can be considered as a plane-parallel 2D-problem, the domain of analysis $\Omega$ being included in the vertical plane $\mathrm{xOy}$.

\section{Mathematical model for the irrigation furrow}

The mathematical model is complex and it includes two modules: a) for the transitory infiltration process in the soil between the furrows and b) for the flow out of the furrow - which may be considered permanent, gradually varied, with a uniformly distributed discharge.

\subsection{The mathematical model for the transitory infiltration}

This model implies four steps: $1^{\circ}$ specification of the analysis domain and its boundaries; $2^{\circ}$ basic equations; $3^{\circ}$ boundary conditions and $4^{\circ}$ initial conditions.

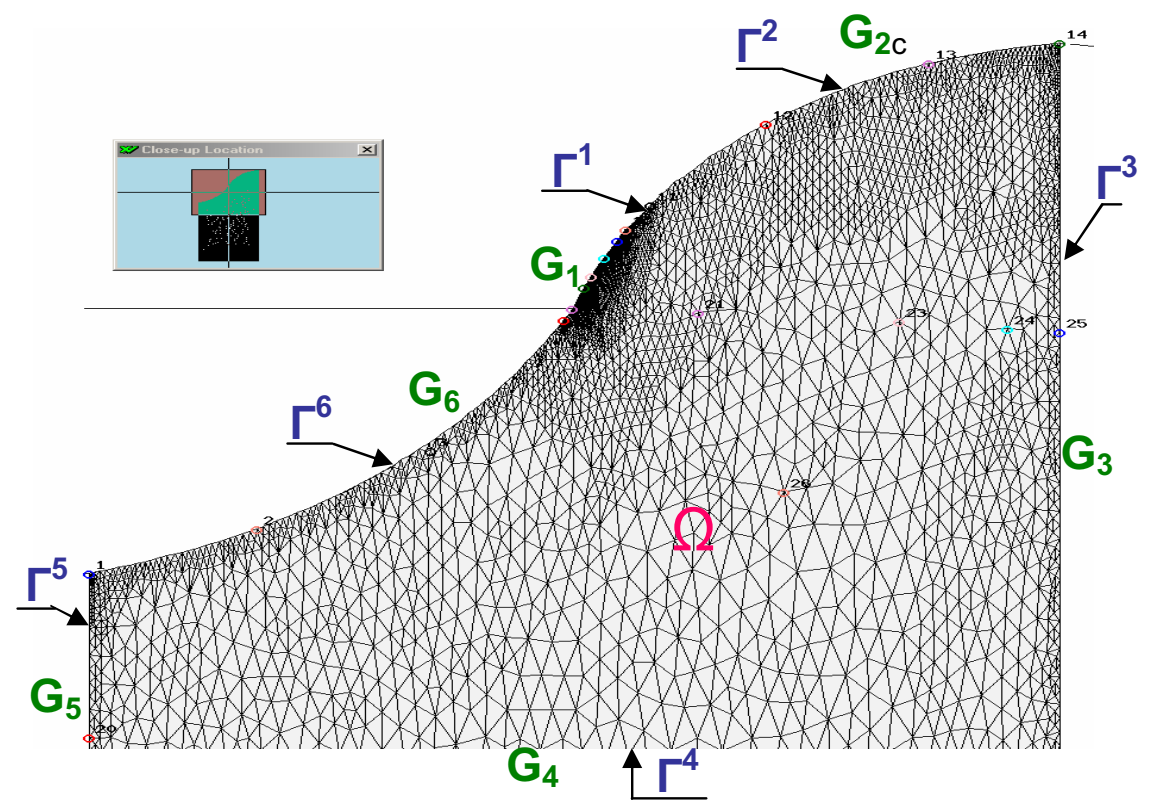

Figure 1: $\quad$ The $\Omega$ domain with 26 observation points (O.P.) and six groups of O.P. 


\subsubsection{Specification of the analysis domain, $\Omega$, and its boundary, $\Gamma$}

We consider within the vertical plane that includes the analysis domain, $\Omega$, a Cartesian coordinate system with a horizontal Ox-axis and a vertical Oy-axis directed upward. The origin $\mathrm{O}$ is placed in the lower left corner and it has the coordinates $\left(x^{0}, y^{0}\right)$.

The domain $\Omega$ is limited like in figure 1: laterally by two vertical lines; on the lower side by the horizontal line $y=y^{0}$ and on the upper side by the curve $y=y_{\text {sup }}(x)$, which is given by the two arcs of circle out of the equations:

$$
y_{\text {sup }}(x)=\left\{\begin{array}{c}
y_{f}+R-\sqrt{R^{2}-\left(x-x^{0}\right)^{2}}, \text { for } x \in\left[x^{0}, x^{0}+R\right] \\
y_{f}+R+\sqrt{R^{2}-\left(x-x^{0}-R\right)^{2}}, \text { for } x \in\left[x^{0}+R, x^{0}+2 R\right]
\end{array}\right.
$$

thus the domain $\Omega$ is defined this way:

$$
(x, y) \in \Omega \Leftrightarrow y \in\left[y^{0}, y_{\text {sup }}(x)\right], x \in\left[x^{0}, x^{0}+2 R\right] .
$$

Because of geometric and functional considerations, the boundary $\Gamma$ of the domain $\Omega$ was divided in $n_{\Gamma}=6$ disjunctive sections, $\Gamma^{i},\left(i=1,2, \cdots, n_{\Gamma}\right)$, so that $\Gamma=\bigcup^{n_{\mathrm{r}}} \Gamma^{i}$. These sections are defined as:

$$
\left\{\begin{array}{c}
\Gamma^{1}: y=y_{\text {sup }}(x), \text { for } x \in\left[x^{0}, x^{0}+R\right] \\
\Gamma^{2}: y=y_{\text {sup }}(x), \text { for } x \in\left[x^{0}+R, x^{0}+2 R-\sqrt{R^{2}-\left(h_{\text {over }}^{\max }\right)^{2}}\right] \\
\Gamma^{3}: y=y_{\text {sup }}(x), \text { for } x \in\left[x^{0}+2 R-\sqrt{R^{2}-\left(h_{\text {over }}^{\max }\right)^{2}}, x^{0}+2 R\right] \\
\Gamma^{4}: x=x^{0}+2 R, \text { for } y \in\left[y^{0}, y_{f}+2 R\right] \\
\Gamma^{5}: y=0, \text { for } x \in\left[x^{0}, x^{0}+2 R\right] \\
\Gamma^{6}: x=x^{0}, \text { for } y \in\left[y^{0}, y_{f}\right]
\end{array}\right.
$$

\subsubsection{Governing equations of flow}

Based on the conceptual model presented above (section 2), the particular mathematical model was inferred by Diersch [3], for the 2D-flow problem with free water level and with distributed sources of volume fluid, $Q_{p}$. This model is defined by the equations of Darcy and respectively by the diffusivity equation:

$$
\begin{gathered}
q_{x}=-k_{r} K \frac{\partial H}{\partial x}, q_{y}=-k_{r} K \frac{\partial H}{\partial y} \\
n_{C} \frac{\mathrm{d} S_{w}}{\mathrm{~d} H} \cdot \frac{\partial H}{\partial t}-K \frac{\partial}{\partial x}\left(k_{r} \frac{\partial H}{\partial x}\right)-K \frac{\partial}{\partial y}\left(k_{r} \frac{\partial H}{\partial y}\right)=Q_{p},
\end{gathered}
$$


where: $H$ is hydraulic head; $q_{x}, q_{y}$ are components of the Darcy flux, directed along the axes of coordinates; $k_{r}$ is relative permeability (hydro-conductivity).

Usually the saturation $S_{w}$ and the relative permeability $k_{r}$ are given [3], respectively, by the constitutive equations $S_{w}=\mathrm{S}_{w}(\psi)$ and $k_{r}=k_{r}(\psi)$, where $\psi$ represents the piezometric head of the water in the ground; as it has been stated above (section 2), for the expression $S_{w}=\mathrm{S}_{w}(\psi)$ was adopted in this article the "van Genuchten-Mualem" model of characteristic humidity. The relation between the height $\psi=\psi(x, y)$ and the hydraulic head $H$ is:

$$
\psi(x, y)=H(x, y)-y \text {. }
$$

\subsubsection{Boundary conditions (B.C.)}

In concordance with the specifications of the conceptual model all the three classical types of boundary conditions have been identified.

\subsubsection{First kind B.C. (Dirichlet type), for $(x, y) \in \Gamma^{2}$ :}

$$
H(x, y, t)=\left\{\begin{array}{c}
a_{i n c}+b_{i n c} \sqrt[3]{t}, \text { for } t \in\left[t_{I}, t_{i n c}(y)\right] \\
y_{f}+h(t), \text { for } t \in\left[t_{i n c}(y), t_{r e m}(y)\right] \\
y+\psi_{F}\left[t-t_{r e m}(y)\right] /\left[t_{F}-t_{r e m}(y)\right], \text { for } t \in\left[t_{r e m}(y), t_{F}\right]
\end{array} .\right.
$$

where $\psi_{I}, \psi_{F}$ represent the piezometric head of the water in the soil at the initial moment $t_{I}$, and at the final moment $t_{F} ; t_{\text {inc }}(y), t_{\text {rem }}(y)$ are the moments at which the water level rises and, respectively, decreases to the value $y$.

The variation law of the water depth in the furrow, $h=h(t)$, can be determined by experimental measurements or by numerical simulation. Using the described model with the characteristic curve of humidity, the heights $\psi_{I}$ şi $\psi_{F}$ can be expressed in function of de saturation degrees $S_{w}^{I}$ and, respectively, $S_{w}^{F}$; for example:

$$
\psi_{I}=-\frac{1}{A_{w}}\left[\left(\frac{S_{w}^{s}-S_{w}^{r}}{S_{w}^{I}-S_{w}^{r}}\right)^{n_{w} / n_{w}-1}-1\right]^{1 / n_{w}} .
$$

3.1.3.2 Second kind B.C., natural B.C., for $(x, y) \in \Gamma_{2}=\Gamma^{1} \cup \Gamma^{4} \cup \Gamma^{6}$ :

$$
\frac{\partial H}{\partial x} n_{x}+\frac{\partial H}{\partial y} n_{y}=0,
$$

where $n_{x}$ and $n_{y}$ are the versors of the normal $\mathbf{n}$ at the border $\Gamma_{2}$. 
3.1.3.3 Third kind B.C. (Chauchy type), for $(x, y) \in \Gamma_{3}=\Gamma^{3} \cup \Gamma^{5}$ :

$$
-k_{r} K \frac{\partial H}{\partial x} n_{x}-k_{r} K \frac{\partial H}{\partial y} n_{y}=\left\{\begin{array}{l}
-\Phi^{\text {out }}(y-H(t, x, y)), \text { for } H(t, x, y)>y \\
-\Phi^{\text {in }}(y-H(t, x, y)), \text { for } H(t, x, y) \leq y
\end{array}\right.
$$

where $\Phi^{\text {out }}$ and $\Phi^{\text {in }}$ are the transfer coefficients through the border $\Gamma_{3}$ in the exterior and, respectively in the interior of the domain $\Omega$.

\subsubsection{Initial Conditions (I.C.)}

At the moment $t=t_{I}$,

$$
H(x, y)=y+\psi_{I}, \text { for }(x, y) \in \Omega,
$$

where the height $\psi_{I}$ is evaluated with the relation (10).

\subsection{Mathematical model for the flow in the furrow}

For the validity check of the hypothesis $4^{\circ}$ from pct. 2, eqn (1) from [1], this has been particularized for horizontal cylindrical channels with a uniformly changing flow-through:

$$
\frac{\mathrm{d} h}{\mathrm{~d} s}=\frac{\frac{s}{A^{2}}\left[2 \frac{\alpha_{0}}{g}-\frac{s}{R_{h} C^{2}}\right]}{\left(q_{\text {max }}\right)^{-2}-\frac{\alpha}{g} \frac{B}{A^{3}} s^{2}}
$$

where: $\alpha_{0}=$ Boussinesq coefficient; $\alpha=$ Coriolis coefficient; $\mathrm{g}=$ gravitational acceleration, $\left[\mathrm{ms}^{-2}\right] ; R_{h}=$ hydraulic radius, $[\mathrm{m}]-R_{h}=A / P$, with $P=$ wetted perimeter, $[\mathrm{m}] ; C=$ Chèzy coefficient - computed with the Manning formula,

$$
C=1 / n_{r} R_{h}^{1 / 6}
$$

with $n_{\mathrm{r}}$ - equivalent roughness coefficient.

For the conceptual furrow's model from section 2, have resulted in the case $h>R$ the following expressions for the geometric and hydraulic parameters of the relations (14) and (15):

$$
\begin{gathered}
B=4 R-2 \sqrt{R^{2}-\left(h_{\text {over }}\right)^{2}} ; \\
P=P_{1}+P_{2}, \text { where } P_{1}=\pi R \text { and } P_{2}=\pi R-2 R \arccos \left(h_{\text {over }} / R\right) ; \\
A=\left[\pi-\arccos \left(h_{\text {over }} / R\right)\right] R^{2}+h_{\text {over }} \sqrt{R^{2}-\left(h_{\text {over }}\right)^{2}} ; \\
n_{r}=\frac{\left(P_{1} n_{r 1}^{3 / 2}+P_{2} n_{r 2}^{3 / 2}\right)^{2 / 3}}{\left(P_{1}+P_{2}\right)^{2 / 3}},
\end{gathered}
$$

where the inferior index 1 stands for the coated section of the furrow, and 2 for the section in direct contact with the soil. 
Eqn (14) has to be resolved with the conditions of limit:

$$
s=0, h=h_{\text {max }} \text {. }
$$

\section{Practical application}

The practical application developed below is aimed to verify the mathematical model presented in section 3, as well as for the evaluation of the watering efficiency by using lined furrows.

The basic technical - centralized in table 2 and in table 4 , rows $1, \ldots, 5$ - have been determined for an experimental model with the length $L_{f}=100 \mathrm{~m}$ and the flow-through $Q_{\text {ups }}=1.5 \mathrm{l} / \mathrm{s}$.

Table 2: $\quad$ Law of water-level variation in the furrow.

\begin{tabular}{|l|l|l|l|l|l|l|}
\hline$t$ (day) & 0.0000 & 0.0040 & 0.0060 & 0.0100 & 0.0190 & 0.0300 \\
\hline$y_{f}+h(t)(\mathrm{m})$ & 0.9272 & 0.9284 & 0.9289 & 0.9301 & 0.9325 & 0.9352 \\
\hline$t($ day $)$ & 0.0400 & 0.1000 & 0.2000 & 0.3400 & 0.4000 & 0.4500 \\
\hline$y_{f}+h(t)(\mathrm{m})$ & 0.9375 & 0.9492 & 0.9617 & 0.9703 & 0.9722 & 0.9734 \\
\hline$t($ day $)$ & 0.5000 & 0.5800 & 0.6200 & 0.6399 & 0.6623 & 0.6882 \\
\hline$y_{f}+h(t)(\mathrm{m})$ & 0.9743 & 0.9754 & 0.9758 & 0.9704 & 0.9650 & 0.9596 \\
\hline$t($ day $)$ & 0.7186 & 0.7559 & 0.8036 & 0.8705 & 0.9818 & 1.3156 \\
\hline$y_{f}+h(t)(\mathrm{m})$ & 0.9542 & 0.9488 & 0.9434 & 0.9380 & 0.9326 & 0.9272 \\
\hline
\end{tabular}

\subsection{Pre-processing of basic data}

For the implementation of the boundary conditions (9), using the program MATLAB Pre_Proc_Furrow.m, have firstly been determined the characteristic moments $t_{\text {inc }}(\bar{y})$ and $t_{\text {rem }}(y)$ for each knot on the border $\Gamma^{2}$ and then the coefficients from the power-laws of variation for $H v s$. the time $\mathrm{t}$ (table 3).

Table 3: $\quad$ The values of the moments $t_{\text {inc }}(y)$ and $t_{\text {rem }}(y)$ and of the coefficients $a_{\text {inc }}(y)$ and $b_{\text {inc }}(y)$ from the boundary conditions (9) at a watering application (extract).

\begin{tabular}{|l|c|c|c|c|c|c|c|}
\hline$y(\mathrm{~m})$ & 0.9290 & 0.9324 & 0.9351 & 0.9385 & 0.9424 & 0.9451 & 0.9483 \\
\hline$t_{i n c}(\mathrm{~d})$ & 0.0063 & 0.0189 & 0.0297 & 0.0451 & 0.0652 & 0.079 & 0.0954 \\
\hline$a_{\text {inc }}$ & -59.071 & -59.068 & -59.065 & -59.061 & -59.058 & -59.055 & -59.052 \\
\hline$b_{\text {inc }}$ & 324.109 & 225.089 & 193.747 & 168.559 & 149.071 & 139.862 & 131.293 \\
\hline$t_{\text {rem }}(\mathrm{d})$ & 12.041 & 0.989 & 0.9297 & 0.8644 & 0.8158 & 0.7886 & 0.7602 \\
\hline
\end{tabular}

\subsection{The simulation of infiltration in a transitory regime}

The infiltration in the soil between the furrows has been simulated numerically using the centralized data from table 4, as well as the software package FEFLOW 5.1. The basic plane of the application (figure 1) has resulted from the representation of the functions (3) and (4) in AUTOCAD. 
Table 4: $\quad$ Entry parameters for numerical simulation.

\begin{tabular}{|c|c|c|c|c|}
\hline No. & Symbol & Nomenclature & U.M. & Values \\
\hline \multicolumn{5}{|c|}{ For eqs (3)...(5) } \\
\hline 1 & $x^{0}$ & $\begin{array}{l}\text { abscise of the lower limit of the } \\
\text { domain }\end{array}$ & (m) & 0.0264 \\
\hline 2 & $y^{0}$ & $\begin{array}{l}\text { ordinate of the lower limit of the } \\
\text { domain }\end{array}$ & (m) & 0.0268 \\
\hline 3 & $R$ & radius of the arc-circle lines & $(\mathrm{m})$ & 0.2500 \\
\hline 4 & $y_{f}$ & ordinate of the thalweg of furrows & $(\mathrm{m})$ & 0.6772 \\
\hline \multicolumn{5}{|c|}{ For unsaturated } \\
\hline 5 & $\varepsilon$ & porosity & (1) & 0.3051 \\
\hline 6 & $K$ & $\begin{array}{l}\text { coefficient of isotropic hydraulic } \\
\text { conductivity }\end{array}$ & $\begin{array}{l}\left(10^{-}\right. \\
4 \mathrm{~m} / \mathrm{s})\end{array}$ & 0.0869 \\
\hline 7 & $S_{w}^{r}$ & residual saturation & (1) & 0.0159 \\
\hline 8 & $n_{w}$ & power exponent & & 1.3868 \\
\hline 9 & $A_{w}$ & $\begin{array}{l}\text { coefficient of the Genuchten-Mualem } \\
\text { law }\end{array}$ & & 7.3055 \\
\hline \multicolumn{5}{|c|}{ Initial condition } \\
\hline 10 & $t_{I}$ & initial time & (day) & 0.0000 \\
\hline \multirow[t]{5}{*}{11} & \multirow{5}{*}{$S_{w}^{\prime}$} & Initial saturation for: & \multirow[t]{5}{*}{ (1) } & \\
\hline & & $y^{0} \leq y \leq 0.05$ & & 0.1382 \\
\hline & & $0.05 \leq y \leq 0.20$ & & 0.11253 \\
\hline & & $0.20 \leq y \leq 0.40$ & & 0.1162 \\
\hline & & $0.40 \leq y \leq y_{\text {sup }}(x)$ & & 0.1091 \\
\hline \multicolumn{5}{|c|}{1 st B.C. } \\
\hline 12 & $y_{f}+h(t)$ & water level in furrow & $(\mathrm{m})$ & table 2 \\
\hline 13 & $t_{i n c}, t_{r e m}$ & $\begin{array}{l}\text { moments at which the water level } \\
\text { decreases to the value } y\end{array}$ & (day) & table 3 \\
\hline 14 & $a_{i n c}, b_{i n c}$ & & & table 3 \\
\hline 15 & $S_{w}^{F}$ & final saturation & & \\
\hline \multicolumn{5}{|c|}{3 st B.C. } \\
\hline 16 & $\Phi^{\text {in }}$ & in transfer coefficient & & \\
\hline 17 & $\Phi^{\text {out }}$ & out transfer coefficient & & \\
\hline
\end{tabular}

\subsection{Post-processing of resulting data}

After the post-processing of the results obtained with FEFLOW_5.1 we have retained the centralized data from table 5, because these are the most significant.

Data from table 5 indicates that: d) the volumic size of the accumulated water in the soil - between the moments $t_{I}$ şi $t_{F}$ - is $0.068 \mathrm{~cm}$, which corresponds to a watering norm of: $0.068 \mathrm{~cm} /(0.5 \mathrm{~m} \mathrm{x} 1 \mathrm{~m})=1374 \mathrm{~cm} / \mathrm{ha}=137.4 \mathrm{~mm}$. 
Table 5: Global quantitative indicators concerning the watering using a lined furrow.

\begin{tabular}{|c|c|c|c|c|c|c|}
\hline $\begin{array}{c}\mathrm{Nr} . \\
\text { crt. }\end{array}$ & Indicator & U.M. & $\begin{array}{c}\text { Initial } \\
\text { values }\end{array}$ & $\begin{array}{c}\text { Final } \\
\text { values }\end{array}$ & $\begin{array}{c}\text { Variations } \\
\text { col. 5 - 4 }\end{array}$ & Observations \\
\hline $\mathbf{1}$ & $\mathbf{2}$ & $\mathbf{3}$ & $\mathbf{4}$ & $\mathbf{5}$ & $\mathbf{6}$ & $\mathbf{7}$ \\
\hline 1 & $\int_{\Omega} \mathrm{d} V$ & m.c. & 0.44994 & 0.44994 & 0 & $\begin{array}{c}\text { Volume in } \\
\text { domain }\end{array}$ \\
\hline 2 & $\int_{\Omega} n \mathrm{~d} V$ & m.c. & 0.13728 & 0.13728 & 0 & $\begin{array}{c}\text { Volume of pores } \\
\text { contained in } \\
\text { domain }\end{array}$ \\
\hline 3 & $\int_{\Omega} n S_{w} \mathrm{~d} V$ & m.c. & 0.01569 & 0.08369 & 0.0680 & $\begin{array}{c}\text { Volume of liquid } \\
\text { phase contained in } \\
\text { domain }\end{array}$ \\
\hline
\end{tabular}

\subsection{Determination of the variation law for the water depth}

Considering eqs (14) and (20) the following entrance data set is given:

$R=0.25 \mathrm{~m}, \alpha=1.1, \alpha_{0}=1.103, g=9.81 \mathrm{~ms}^{-2}, h_{\max }=0.30 \mathrm{~m}$, $q_{\max }=0.00075 \mathrm{~m}^{2} \mathrm{~s}^{-1}, n_{1}=0.01, n_{2}=0.025, n_{r}=0.012$.

The variation law of the water depth along the furrow, $h=h(s)$, is represented by the solution of the differential equation (14), with the limit condition (20). This way it is visible that, for $s \in[1,100]$ the water depth increases from $0.30 \mathrm{~m}$ to $0.30000051 \mathrm{~m}$, thus it is growing only by $0,00017 \%$ - which confirms the rightness of the hypothesis $4^{\circ}$ and assures that the uniformity coefficient tends to a value about 1 .

\section{Conclusions and future perspectives of the researches}

The analysis of the obtained results for the lined watering furrows allows the following statements:

$1^{\circ}$ The uniformity of the watering along the furrow is astonishing good.

$2^{\circ}$ An efficient control of the water losses in deeper soil layers is assured even on grounds with a higher permeability.

$3^{\circ}$ The effectiveness of the field waterings is high, but it depends on the amount of the irrigation norm and on remnant of water volume in the lined furrows after the watering period.

$4^{\circ}$ The effectively cultivated surface is reduced in comparison with the uncoated furrows, but it can be increased by using only one furrow for two plant rows.

In the future we will extend the researches also on the thermal furrows with a positive bottom gradient.

We will analyze also - from a technical and an economical sight - the possibility to utilize coated furrows exclusively for irrigation purposes. 


\section{References}

[1] Popescu, St. \& Giurma, C.R., About a new application of the fundamental formula for the gradually varied motion in river bed. Bulletin I.P. Iasi, XLV (IL), Hidrotehnica, pp. 5-9, 2000.

[2] Nitescu, E., Popescu, St., Giurma, I., Bartha, I. \& Nitescu, C., Technology for using energy of geothermal water for crops. Proc. of the Int. Conf., "Ag Energy '99", vol.2, eds. Athens, Greece, pp. 230-239, 1999.

[3] Diersch, H.-J.G. Reference Manual, 2002, FEFLOW (Finite Element Subsurface Flow \& Transport Simulation System), WASY Institute, Berlin, Germany.

[4] Final Report of NATO-PO-Irrigation, 1994, Development of Irrigation Technologies for Southern Portugal, Lisbon, Portugal 